\title{
Preliminary characterization of an experimental breast cancer cells brain metastasis mouse model by MRI/MRS
}

\author{
R. V. Simões · A. Martinez-Aranda • B. Martín • \\ S. Cerdán · A. Sierra · C. Arús
}

Received: 2 November 2007 / Revised: 28 March 2008 / Accepted: 11 April 2008 / Published online: 31 May 2008

(C) ESMRMB 2008

\begin{abstract}
Purpose Chemotherapy increases survival in breast cancer patients. Consequently, cerebral metastases have recently become a significant clinical problem, with an incidence of $30-40 \%$ among breast carcinoma patients. As this phenomenon cannot be studied longitudinally in humans, models which mimic brain metastasis are needed to investigate its pathogenesis. Such models may later be used in experimental therapeutic approaches.

Material and methods/results We report a model in which $69 \%$ of the animals (9/13 BALB/c nude mice) developed MRdetectable abnormal masses in the brain parenchyma within a 20 to 62-day time window post intra-carotid injection of $435-\mathrm{Br} 1$ human cells. The masses detected in vivo were either single ( 7 animals) or multiple ( 2 animals). Longitudinal MR (MRI/MRS) studies and post-mortem histological data were
\end{abstract}

R. V. Simões $(\varangle) \cdot$ C. Arús

Grup d'Aplicacions Biomèdiques de la Ressonància Magnètica

Nuclear (GABRMN), Universitat Autònoma de Barcelona,

Cerdanyola del Vallès, Spain

e-mail: rsimoes@carbon.uab.es

R. V. Simões · C. Arús

Centro de Investigación Biomédica en Red en Bioingeniería,

Biomateriales y Nanomedicina (CIBER-BBN),

Cerdanyola del Vallès, Spain

R. V. Simões

Centro de Neurociências e Biologia Celular de Coimbra (CNC),

Universidade de Coimbra, Coimbra, Portugal

A. Martinez-Aranda · B. Martín · A. Sierra

Centre d'Oncologia Molecular, Institut d'Investigació Biomèdica

de Bellvitge (IDIBELL), CSUB, Barcelona, Spain

S. Cerdán

Departamento de Modelos experimentales de enfermedades humanas, Instituto de Investigaciones Biomédicas "Alberto Sols" UAM-CSIC, Madrid, Spain correlated, revealing a total incidence of experimental brain metastases of $85 \%$ in the cases studied (11/13 animals). ADC maps perfectly differentiated edema and/or CSF areas from metastasis. Preliminary MRS data also revealed additional features: decrease in $N$-acetyl aspartate (NAA) was the first MRS-based marker of metastasis growth in the brain (micrometastasis); choline-containing compounds (Cho) rose and creatine $(\mathrm{Cr})$ levels decreased as these lesions evolved, with mobile lipids and lactate also becoming visible. Furthermore, MRS pattern recognition-based analysis suggested that this approach may help to discriminate different growth stages. Conclusions This study paves the way for further in vivo studies oriented towards detection of different tumor progression states and for improving treatment efficiency.

Keywords Brain metastasis - Breast cancer - Proton magnetic resonance spectroscopy · Magnetic resonance imaging $\cdot$ Pattern recognition

$\begin{array}{ll}\text { Abbreviations } \\ \text { ADC } & \text { Apparent diffusion coefficient } \\ \text { ASCII } & \text { American Standard Code for Information } \\ & \text { Interchange } \\ \text { CBF } & \text { Cerebral blood flow } \\ \text { CBV } & \text { Cerebral blood volume } \\ \text { CE-T1 MRI } & \text { Contrast-enhanced T1 MRI } \\ \text { DAB } & \text { Diaminobenzidine } \\ \text { DMEM/F12 } & \text { Dulbecco's Modified Eagle Medium with } \\ & \text { nutrient mixture F12 Ham } \\ \text { d_PI } & \text { Days post-injection } \\ \text { DWI } & \text { Diffusion weighted imaging } \\ \text { FBS } & \text { Fetal bovine serum } \\ \text { FOV } & \text { Field of view } \\ \text { GFP } & \text { Green fluorescent protein } \\ \text { GUI } & \text { Graphical user interface }\end{array}$




$\begin{array}{ll}\text { H\&E } & \text { Hematoxylin-eosin } \\ \text { IHC } & \text { Immunohistochemistry } \\ \text { ic } & \text { Intracarotid } \\ \text { ip } & \text { Intraperitoneal } \\ \text { LB } & \text { Line broadening } \\ \text { HBSS } & \text { Hanks' balanced salt solution } \\ { }^{1} \text { H MRS } & \text { Proton magnetic resonance spectroscopy } \\ \text { ML } & \text { Mobile lipids } \\ \text { MRI } & \text { magnetic resonance imaging } \\ \text { MTX } & \text { Matrix size } \\ \text { MSME } & \text { multi-slice multi-echo } \\ \text { NEX } & \text { Number of averages } \\ \text { OCT } & \text { Tissue freezing medium } \\ \text { PCNA } & \text { Proliferating cell nuclear antigen } \\ \text { PRESS } & \text { Point resolved spectroscopy } \\ \text { RARE } & \text { Rapid acquisition by relaxation enhancement } \\ s c & \text { Subcutaneous } \\ \text { SNR } & \text { Signal to noise ratio } \\ \text { SPF } & \text { Specific pathogen free } \\ \text { TAT } & \text { Total acquisition time } \\ \text { TE } & \text { Echo time } \\ \text { TR } & \text { Repetition time } \\ \text { VAPOR } & \text { Variable pulse power and optimized } \\ \Delta v_{1 / 2} & \text { relaxation delays } \\ \Delta & \text { MRS peak width at half height } \\ \delta & \text { Big delta } \\ & \\ \text { Small delta } \\ \text { MA }\end{array}$

\section{Introduction}

Breast cancer is the leading cause of death in women between the ages of 35 and 55 [1]. At this age range, breast cancers are also very prone to metastasize to lymph nodes, bone, liver, lungs and brain [2,3]. About $30-40 \%$ of patients with disseminated breast carcinoma develop metastasis in the CNS, $15 \%$ of which with a median survival of 1 year [4] despite the standard treatment. In fact, the metastasis of breast cancer to either the brain parenchyma or the leptomeninges is generally a late feature of metastatic disease.

Metastasis is a complex multistep process [5] which can be studied both in vitro, using molecular biology techniques, and in vivo. As these pathologies cannot be studied longitudinally in humans, due to evident ethical reasons, in vivo follow-up studies require animal models that can accurately recapitulate the process observed in humans.

There is abundant information on animal models of primary breast cancer, e.g. based on the injection of tumor cells in the mammary fat pad [6]. However, models which mimic brain metastasis are needed to help understanding this pathogenesis and for use in experimental therapeutic approaches. In 1988, Schackert and Fidler described an animal model of brain metastasis based on the intracarotid (ic) injection of human cell lines in nude mice [7]. They used this model to characterize melanoma brain metastasis and different types of carcinoma [8]. The same model has already been used in immunohistochemical studies of different cell lines [9] and also to study in vivo melanoma brain metastasis by magnetic resonance imaging (MRI) [10]. More recently, MRI has been used with another mouse model of human brain metastasis [11] to track single metastatic cells in the brain [12].

The MRI and MR spectroscopy (MRS) are two powerful non-invasive techniques that are normally available at any medical center equipped with a clinical MR scanner. MRI provides structural characterization of brain tissue, e.g. by T2 weighted and CE-T1 images. It can also be used to measure parameters of biophysical interest (to calculate ADC values, measure $\mathrm{CBF}$ and $\mathrm{CBV}$, etc.). In contrast, MRS can provide biochemical information, i.e. the metabolomic profile in specific regions of the brain (volumes of interest, VOI) [13-15]. Although both techniques are complementary, normally only MRI is used in hospitals as a routine tool for brain tumor diagnosis and prognosis. Therefore, it appears that the clinical MRS performance needs to be improved. To achieve this, normalized acquisition and post-processing protocols should be established. In addition, robust decision support systems (DSS), which can help in the pattern classification of spectra [16], should be developed and implemented.

The main objective of this study was to optimize a longitudinal MRI/MRS method for analyzing pathogenic aspects of brain metastasis growth. This method could be used to monitor metabolic changes during metastasis development and therapy response. Accordingly, we have characterized in vivo the morphologic and metabolic development pattern of brain metastases induced in nude mice by ic injection of 435-Br1 human mammary carcinoma cells, a brain metastasis variant of the MDA-MB-435 parental cell line (435p in short) [17]. For this, we used different MRI approaches (T2 and CE-T1 weighted images and diffusion imaging) and ${ }^{1} \mathrm{H}$ MRS (at both short and long echo times, TE). MRI data was then compared with the post-mortem histological analysis of the dissected brains. MRS data was used in a preliminary and tentative pattern classification attempt of the different progression stages observed, using a DSS developed for human brain tumors.

\section{Materials and methods}

Cells and animals

Both 435-Br1 human mammary carcinoma cells, originally established from a brain metastasis in a nude mouse orthotopically inoculated with the parental cell line (435p), and $435 \mathrm{p} / \mathrm{GFP}$ cells, from a parental cell line transfected with the pCEP4 expression vector containing the GFP (Invitrogen, San Diego, CA, USA) [18], were used in this work. 
These were maintained under standard conditions in $1: 1(\mathrm{v} / \mathrm{v})$ mixture of DMEM and Ham F12 medium, DMEM/F12 (Life Technologies, Inc. Gibco BRL, Gaithersburg, MD), supplemented with $10 \%$ fetal bovine serum (FBS), $1 \mathrm{mM}$ pyruvate, and $2 \mathrm{mM}$ L-glutamine in a $5 \% \mathrm{CO}_{2}$ environment at $37^{\circ} \mathrm{C}$ using a humidified incubator [17]. For $B A L B / c$ nude mice inoculation, 435-Br1 cells in exponential growth phase were first treated with Trypsine-EDTA (Life Technologies) for $1 \mathrm{~min}$ at room temperature. They were then washed twice in HBSS and counted using a Neubäuer chamber. Viability was always between 90 and 97\%, as measured by Trypan-Blue exclusion. 435-Br1 cells were then resuspended in HBSS to obtain a final concentration of $1 \times 10^{6}$ cells $/ 100 \mu \mathrm{l}$ (aliquot used for inoculation).

Thirteen female $22-24 \mathrm{~g}$ athymic $B A L B / c$ nude mice (Charles-River, France) were used in this study of brain metastasis induction. Animals were housed at the IDIBELL animal facility in SFP conditions, at $20-24^{\circ} \mathrm{C}$ cage temperature, $60 \%$ relative humidity, $12-12 \mathrm{~h}$ light-dark periods, and were allowed free access to UV irradiated water and an adequate sterile diet. Control experiments were performed with two female 30-40 g CD 1 mice (Charles-River), as described in next section.

\section{Induction of brain metastasis}

Brain metastases were generated by inoculation of $1 \times 10^{6} 435$-Br 1 cells (resuspended in $100 \mu \mathrm{lBSS}$ ) into the internal carotid artery of thirteen mice, using a slight modification of a previously described method [7]. Briefly, mice were anesthetized intraperitoneally (ip) with ketamine/xylazine $(100 / 10 \mathrm{mg} / \mathrm{kg})$ and placed supine under a dissecting microscope. After the right carotid artery was exposed, the common carotid was permanently clamped with 5.0 suture silk proximal to the injection point. Both the external carotid and the occipital branch were temporarily clamped with 7.0 silk suture. A 34G Hamilton needle (Bonaduz, Switzerland) was then used to deliver $1 \times 10^{6}$ cells into the internal carotid lumen. At approximately $20 \mathrm{~s}$ post-injection, the suture clamping both the external carotid artery and the occipital branch was removed. This procedure took about $1 \mathrm{~h}$ per animal and was performed in sterile conditions (laminar flux cabin) near a dry heat source to prevent body temperature of the animal from dropping during anesthesia. Following surgery, animals received $20 \mathrm{ml} / \mathrm{kg}$ subcutaneous (sc) isotonic glucosaline solution $(0.9 \% \mathrm{NaCl}, 5 \%$ glucose $)$ to avoid dehydration and $0.2 \mathrm{mg} / \mathrm{kg}$ of buprenorphine (analgesia), both administered for the following 2 days. When mice presented visible signs of cachexia, due to metastasis growth, or other physical evidence of pain and suffering, they were sacrificed by injection of pentobarbital, $200 \mathrm{mg} / \mathrm{kg}, 60 \mathrm{mg} / \mathrm{ml}$. This procedure was approved by the 1DIBELL, UAB and IIB Animal Healthcare Committees.
To optimize surgical conditions, we used two $C D 1$ mice inoculated with $1 \times 10^{6}$ in $50 \mu \mathrm{l} 435 \mathrm{p} / \mathrm{GFP}$ cells injected into the right internal carotid artery. In order to monitor the location of the injected cells in the central nervous system [19] at different time points, one animal was sacrificed at $5 \mathrm{~min}$ post-inoculation while the other one was sacrificed right after the inoculation, both with the $\mathrm{CO}_{2}$-breathing method. The brains were then removed and fixed for histological analyses as explained in the "histological analysis" section.

\section{In vivo set-up}

In vivo MR studies were carried out on a high-field horizontal spectrometer (Bruker PharmaScan 7.0 Tesla, Ettlingen, Germany) equipped with actively shielded gradients (300 $\mathrm{mT} / \mathrm{m}$ ) and a $23 \mathrm{~mm}$ diameter birdcage resonator specially designed for mouse head studies. Anesthesia was performed using isoflurane at $1-2.5 \%$ in $\mathrm{O}_{2}$, maintaining the respiratory frequency between 40 and 60 breaths/min, as monitored by BioTrigg equipment (Bruker). Animal body temperature was maintained using a heated water blanket. Tumors were studied by MRI/MRS as described in the next section.

\section{MRI acquisition and post-processing}

Animals were studied by T2, CE-T1 and diffusion weighted imaging (DWI). Single-voxel proton spectroscopy ( $\left.{ }^{1} \mathrm{H}-\mathrm{MRS}\right)$ was also used at two echo times (TE: 35 and $136 \mathrm{~ms}$ ), as described in more detail in the next section. For this, the voxel was always positioned inside the brain parenchyma and centered in or around the abnormal mass detected by MRI; in the case of longitudinal studies, voxel positions were reproduced as well as possible (visual confirmation). All MR studies were performed at the SIERMAC (NMR facility of the Instituto de Investigaciones Biomédicas "Alberto Sols", UAM-CSIC, Madrid, Spain), according to protocols approved by the local animal healthcare committee for animal handling in MR experiments.

Acquisition parameters for T2-W MRI were as follows: RARE sequence (turbo factor, 8); field of view (FOV), $20 \times 20 \mathrm{~mm}$; matrix (MTX), 256×256 $(78 \times 78 \mu \mathrm{m} /$ pixel); number of slices (NS), 14; slice thickness (ST), $1 \mathrm{~mm}$; interslice distance (ISD), $1.1 \mathrm{~mm}$; TR/TE, 2,500/60 ms; number of averages (NEX), 4; total acquisition time (TAT), $5 \mathrm{~m} 20 \mathrm{~s}$. Acquisition parameters for CE-T1 MRI (Gd-DTPA bolus injection in the tail vein at $0.2 \mathrm{mmol} / \mathrm{kg}$ previous to MR acquisition): MSME sequence; FOV, 20×20 mm; MTX, 256×256 $(78 \times 78 \mu \mathrm{m} /$ pixel $) ; \mathrm{NS}, 14 ; \mathrm{ST}, 1 \mathrm{~mm}$; IST, $1.1 \mathrm{~mm}$; TR/TE, 350/11.5 ms; NEX, 4; TAT, $5 \mathrm{~m} 41 \mathrm{~s}$. The volume rendering of tumor masses detected in CE-T1 images was obtained by post-processing as follows: abnormal mass(es) were highlighted in each image of the T1 sequence using a manually defined region of interest (ROI) for each individual mass. 
The given areas for each ROI were then added and multiplied by the inter-slice distance. This process was performed using Image-J software [20]. Acquisition parameters for DWI were as follows: Stejskal-Tanner sequence, one gradient for diffusion $(\mathrm{read}) ; 3 \mathrm{~b}$ values $\left(100,400,800 \mathrm{~s} / \mathrm{mm}^{2}\right) ; \Delta / \delta$, $8.52 / 5.00 \mathrm{~ms}$; FOV, $20 \times 20 \mathrm{~mm}$; MTX, $128 \times 128(156 \times 156$ $\mu \mathrm{m} /$ pixel); NS, 6; slice thickness, $1 \mathrm{~mm}$; IST, $1.1 \mathrm{~mm}$; TR/TE, $3,000 / 20 \mathrm{~ms}$; NEX, 1; TAT, $19 \mathrm{~m} 15 \mathrm{~s}$. The images obtained were then processed to generate ADC maps with interactive data language (IDL) home written software [21].

\section{MRS acquisition and post-processing}

${ }^{1} \mathrm{H}-\mathrm{MRS}$ acquisition parameters were as follows: PRESS sequence with VAPOR for water suppression; voxel volume, $3 \times 3 \times 3 \mathrm{~mm}(27 \mu \mathrm{l})$; TR/TE, $3,000 / 35$ or $136 \mathrm{~ms}$ (short and long TE, respectively); number of scans (NS), 128; TAT, $6 \mathrm{~m} 5 \mathrm{~s}$; receiver gain $(\mathrm{RG})$, constant value $(40,000)$. Spectra were then processed using MestReC software [22]: zero filling of 4,096 to 8,192 points, 1,3 or $7 \mathrm{~Hz}$ line broadening (for $\Delta v_{1 / 2}$ measurement of non-suppressed water peaks and metabolite peaks in water-suppressed spectra and displayed spectra, respectively) and zero order phase correction. For the spectral analysis, absolute intensity values were depicted for the peaks of interest. A prototype version of a DSS developed for pattern recognition of human brain tumor spectra, SV INTERPRET v1.2 [23,24], was used to tentatively follow the pattern evolution of spectra acquired at short and long TEs in a longitudinal study of metastasis progression. To attain this, the ASCII format of each spectrum (obtained with MestRe-C) was normalized to unit length using the following formula (strategy already applied to human brain tumor data analyzed for the DSS development [16]):

$I_{\text {norm } i}=\frac{I_{\text {real } i}}{\sqrt{\sum_{\mathrm{ppm}=-2.7}^{7.1} I_{\text {real }^{2}}}}$

$I_{\text {norm }}$ and $I_{\text {real }}$ refer to the intensities at each data point in the normalized spectra and in the real part of the acquired spectra, respectively. Subsequently, the normalized ASCII file was fed into the DSS and evaluated as described in [24].

Histological analysis

Mice brains were fixed after sacrifice in $4 \%$ paraformaldehyde for $24 \mathrm{~h}$, followed by $30 \%$ sucrose for another $24 \mathrm{~h}$. The tissue was then OCT-embedded (tissue freezing medium, Sakura Tissue-Tek ${ }^{\circledR}$ ) before being frozen in dry ice. Samples, which were kept at $-80^{\circ} \mathrm{C}$, were cut into $5 \mu \mathrm{m}$ coronal sections for evaluation (cryostate at $-27^{\circ} \mathrm{C}$ ). In immunofluorescence control studies ( $C D 1$ mice), sections were directly analyzed on a fluorescence microscope (Olympus IX70) with two filters:one for visible light (morphological analysis) and one for fluorescence (GFP-labeled tumor cell detection). In MR longitudinal cases (nude mice), metastatic involvement was explored in each section after classic hematoxylin-eosin (H\&E) staining.

The proliferation state of metastasis was assessed by immunohistochemistry (IHC) using specific PCNA (proliferating cell nuclear antigen) antibody sc-56 (Santa Cruz Biotechnology, Santa Cruz, CA, USA), clone PC10 at 1:50 dilution (PBS-BSA 2\% solution incubated overnight at $4{ }^{\circ} \mathrm{C}$ ). A biotinylated anti-mouse secondary antibody diluted in PBS-BSA 2\% at 1/2,000 (Pierce, Perbio Science Ltd., Cheshire, UK) was incubated for $30 \mathrm{~min}$ at room temperature, following DAB (diaminobenzidine) staining and counterstaining with hematoxylin. IHC were visualized on an Olympus BX60 microscope (Olympus Optical Co., LTD, Japan) and digitalized with a camera and using the Spot 4.2 software (Diagnostic Instruments, Inc, Sterling Heights, MI, USA). For each sample, three fields containing 200 cells were counted for positive PCNA cells (results shown in results section as average percentage).

\section{Results}

\section{Control fluorescence studies}

Fluorescence histological analysis from two CD1 mouse brains (previously inoculated with 435-Br1/GFP cells and sacrificed at 0 and 5 min post-injection), showed cells in the lumen of parenchymatous microvessels in both cases, revealing that they had reached the brain parenchyma microvessels, as expected (Fig. 1a).

\section{MRI and histological analysis}

Approximately 2 weeks after injection of $435 / \mathrm{Br}-1$ cells in nude mice, animals recovered their original weight and MR monitoring was started. Longitudinal MRI/MRS studies were performed in mice up to 32-92 days post-injection of cells, days_PI (except for the case of Nude 2, studied for 265 days). The number of explorations carried out ranged between 1 and 6 , depending on the availability of spectrometer time and overall survival of the animals investigated. T2 and CE-T1 weighted images were used to detect metastasis and localize them in the brain parenchyma. Metastases were first detected between 20 and 62 days post-injection in different brain regions for each afflicted animal (Nude 1, 5, 6, 7, 9, 11, 13: hypothalamus; Nude 3: cerebellum-right hemisphere region; Nude 8:cortex, hippocampus, ventricle, frontal lobe and hypothalamus). This is summarized in Table 1.

In some animals, tumor masses were found in other regions of the body besides the brain. These included the right jaw (7 animals, 6 also with a brain tumor detected) and soft tissue in the neck (1 animal: Nude 10). Tumors detected in 


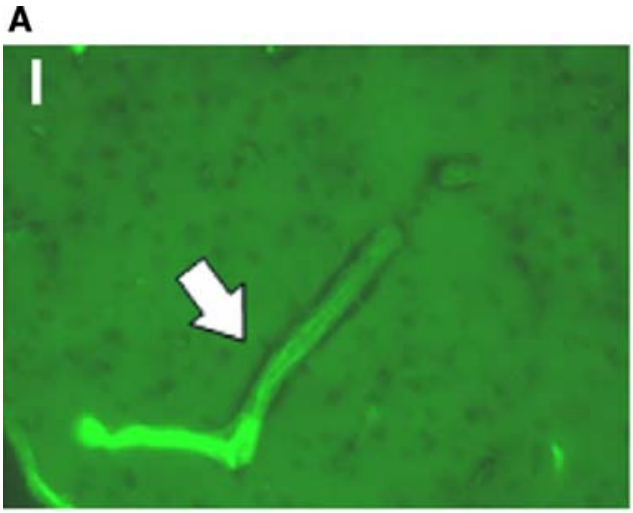

B

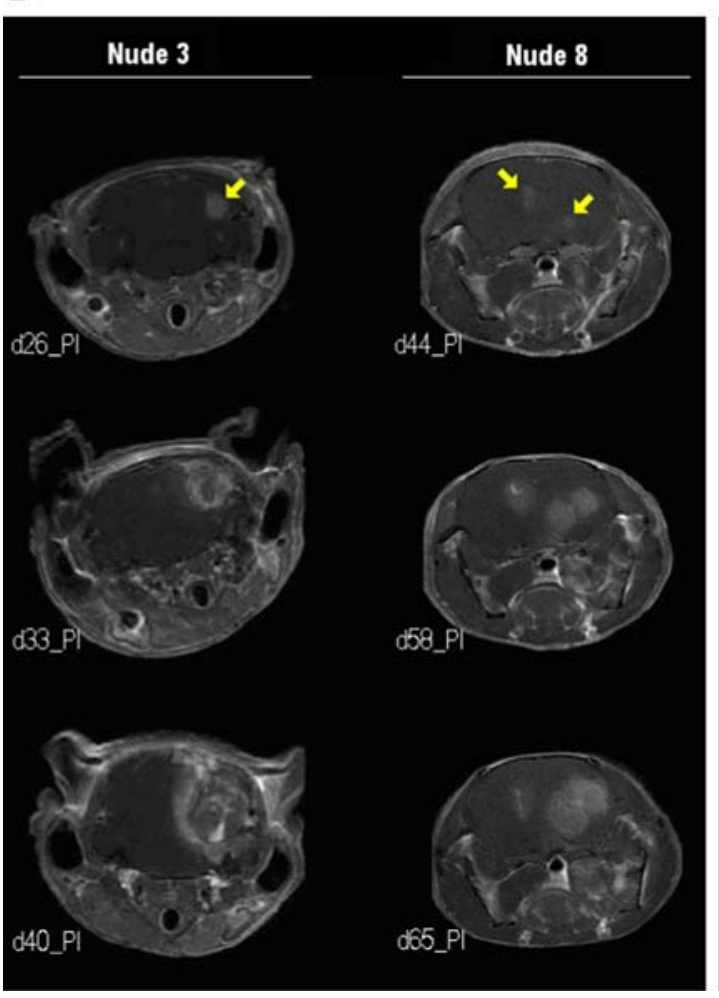

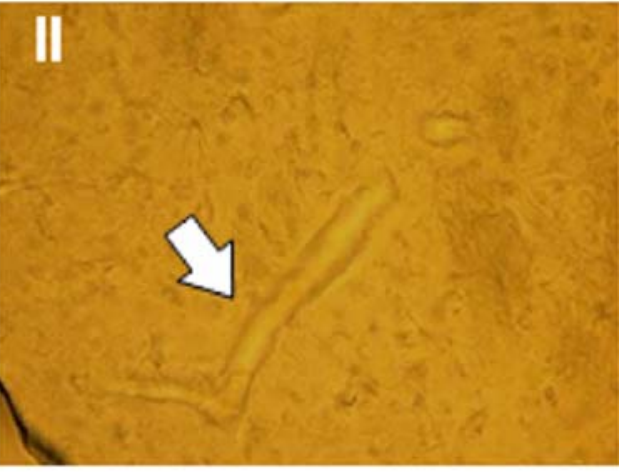

C

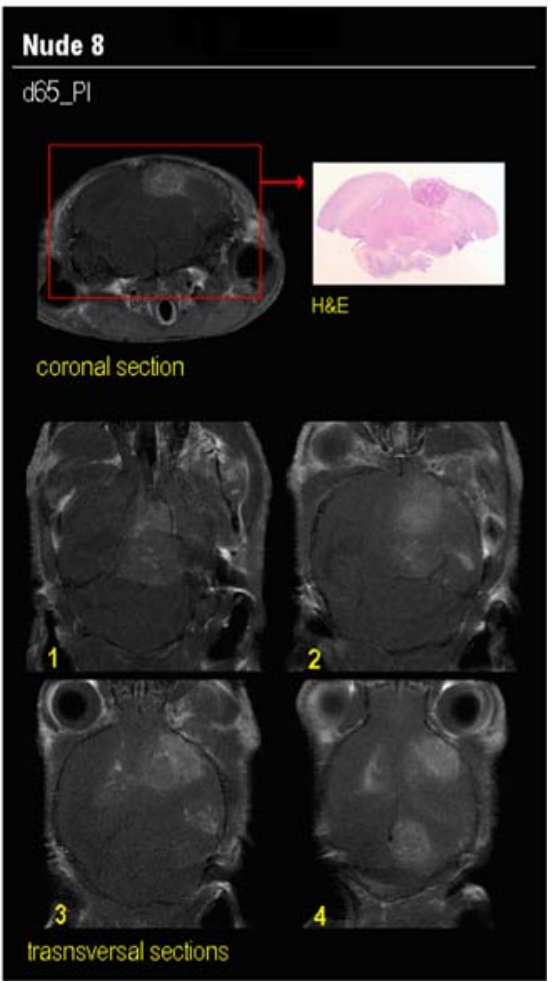

Fig. 1 a Histological analysis of $C D 1$ mouse brain: animal sacrificed 5 min post-i.c. inoculation of $435-\mathrm{Br} 1$ human breast cancer cells transfected with GFP (435-Br1/GFP). Injected tumor cells reached the cerebral parenchyma microvessels (white arrow): (I) fluorescent signal from cells (bright green over a darker background); (II) capillary morphology in brain parenchyma, same slice as in "I" but using visible light. Images: $20 \mu \mathrm{m}$ thickness $/ 40 \times$ enlargement. b Longitudinal studies of tumor progression using CE-T1. Metastases are seen in coronal sections as bright spots inside the brain parenchyma. Nude 3: images obtained at days 26, 33 and 40 post-injection (d_PI) from top to bottom; metastasis

the jaw (28-38 days_PI), normally evolved rapidly, causing feeding problems in the afflicted animals. This eventually led to ending the MR studies before brain tumor masses could be further monitored (in 5 cases: Nudes $3,7,8,9,11$ ) or even detected (Nude 12). Furthermore, we cannot discard effects of repeated and long-term anesthesia contributing to death in 6 of the 13 cases studied (Nudes 1, 2, 4, 5, 6 and 13). first detected at d26_PI as a single mass (highlighted by yellow arrow). Nude 8: coronal sections obtained at days 44, 58 and 65 PI; metastasis first detected at d44_PI as multiple masses that infiltrate through the brain parenchyma (two highlighted by a yellow arrow). C post-mortem histology studies. Nude 8 at d65_PI. Top: CE-T1 MRI coronal section (left) obtained in vivo from the position highlighted below and postmortem hematoxylin-eosin (H\&E) staining of a $5 \mu \mathrm{m}$ slice from that region (insert at right, $10 \times$ magnification). Bottom: four transversal sections (1-4, anterior to posterior) obtained by CE-T1 MRI

Figure 1b shows two examples of longitudinal studies at different days post-injection of metastatic cells. The growth of brain metastases is well observed in both cases, either as one localized mass whose size increased with time (Nude 3), or as multiple masses that spread over the brain parenchyma (Nude 8). Post-mortem histological analyses in transversal and coronal slices were carried 
Table 1 Summary of first detection of in vivo brain and jaw metastases for each $B A L B / c$ nude mouse at different days post-injection of 435 -Br1 cells (d_PI)

\begin{tabular}{|c|c|c|c|c|c|c|c|c|}
\hline \multirow[t]{3}{*}{ Mouse (Nude) } & \multicolumn{4}{|c|}{ MR monitoring } & \multirow{3}{*}{$\begin{array}{l}\text { Death } \\
\text { (d_PI) }\end{array}$} & \multirow{2}{*}{\multicolumn{3}{|c|}{$\frac{\text { Histology }}{\text { (Metastasis, Yes/No) }}$}} \\
\hline & \multirow[t]{2}{*}{ (\#) } & \multicolumn{3}{|c|}{ (Metastasis, d_PI) } & & & & \\
\hline & & Нyp & Jaw & $\mathrm{uBP}$ & & Brain & Lung & Liver \\
\hline 1 & 5 & 35 & 28 & - & $54 \mathrm{~b}$ & & & \\
\hline 2 & 4 & - & - & - & $265 b$ & Yes & No & No \\
\hline 3 & 3 & 26 & - & 26 & 42 & Yes & No & No \\
\hline 4 & 3 & - & - & - & $45 \mathrm{a}$ & No & Yes & No \\
\hline 5 & 1 & 20 & - & - & $32 b$ & & & \\
\hline 6 & 8 & 62 & - & 62 & 92 & Yes & No & No \\
\hline 7 & 4 & 46 & 30 & 46 & 51 & Yes & Yes & No \\
\hline 8 & 6 & 30 & 37 & 37 & 61 & Yes & Yes & No \\
\hline 9 & 3 & 48 & 31 & 48 & 52 & Yes & No & No \\
\hline 10 & 2 & - & - & - & 48 & Yes & Yes & No \\
\hline 11 & 1 & 38 & 38 & - & 50 & Yes & Yes & No \\
\hline 12 & 3 & - & 34 & - & 45 & No & Yes & No \\
\hline 13 & 1 & 27 & 27 & - & $36 a$ & & & \\
\hline
\end{tabular}

“\#”, number of MR explorations per animal; $u B P$, upper brain parenchyma; Hyp, hypothalamus; “-”, metastasis no detected. With respect to death (time shown as d_PI), animals were sacrificed because of symptoms or, in some cases, died during the MR exploration (a) or while recovering from anesthesia (b). Metastases presence in the brain, lung and liver, as detected by post-mortem histological analysis, is also summarized for the cases studied ("empty cells", sample not available)

out in most cases to confirm the extension of the disease (Fig. 1c).

CE-T1 images were further used for volume rendering of metastasis at each progression stage (Fig. 2a). This enabled us to determine growth kinetics curves for each afflicted animal. Each time series was adjusted to a polynomial function (linear when only two points were available). When taken together, this allowed us to generate an average growth curve, as shown in Fig. 2b. Thus, $69 \%$ of the animals (9/13 mice) developed MR-detectable abnormal masses in the brain parenchyma within a 20-62 days time window PI. These masses were either single ( 7 animals) or multiple (2 animals).

Diffusion weighted images (DWI) were also acquired. Only one diffusion axis gradient was used $\left(\mathrm{G}_{\mathrm{read}}\right)$, assuming for the calculations an isotropic diffusion in metastatic regions. The DWI were used to generate apparent diffusion coefficient (ADC) maps in different coronal slices from neck to snap (Fig. 3). Metastatic regions in the brain parenchyma (color coded in green) had higher ADC values than non-afflicted tissues (blue color): $0.88 \pm 0.07$ vs. $0.54 \pm 0.05 \times 10^{3} \mathrm{~mm}^{2} / \mathrm{s}$, respectively, for the example cases shown. Furthermore, ADC maps perfectly differentiated edema and/or CSF areas (bright regions shown in T2 brain images and color coded in green-yellow-red in ADC maps) from metastases.

Correlation of in vivo MRI analysis with post-mortem histology results of sequential coronal tumor sections was performed for the fixed brains of 10 of the 13 cases studied
(3 samples could not be used for histological analysis purposes). These included 6 of the 9 MRI-detected metastases cases (Fig. 4), which presence was confirmed in all cases. Occurrence of metastases was also confirmed in 2 of the 4 non MRI-detected metastases cases. Altogether, in vivo and post-mortem data indicates occurrence of metastases in 11 of 13 animals studied ( $85 \%$ incidence). Histology results also indicate lung metastasis presence in 6 cases ( 4 with brain metastasis), not (yet) affecting the lobules in any of the studied cases, while no liver metastases were detected in any case. The jaw masses seen in vivo were confirmed (for one case) as metastases.

Additional PCNA analysis in $20 \mu \mathrm{m}$ slides showed some heterogeneity in the proliferation pattern of these metastases, particularly when comparing masses seen in hypothalamus (Hyp) with those detected in the upper brain parenchyma (uBP)—Nude 3 (Fig. 4a): 82\% of PCNA positive cells (Hyp); Nude 8 (Fig. 4b): 40\% (uBP), 29\% (uBP) and 15\% (Hyp); Nude 9 (Fig. 4c): $79 \%$ (uBP) and 65\% (Hyp).

\section{MRS}

The MRS was conducted in a total of 10 animals, 8 of which harboring brain metastases. This was performed by single voxel ${ }^{1} \mathrm{H}$-MRS, at short and long TE (35 and $136 \mathrm{~ms}$, respectively). Due to field homogeneity problems and/or difficulties in fitting the metastasis region(s) inside the voxel (e.g., masses in hypothalamus), the metabolic pattern of these 
Fig. 2 a Protocol used for volume rendering of abnormal masses found inside the brain parenchyma. b Metastasis growth patterns (volume in $\mu \mathrm{l}$ ) inside the brain parenchyma at different days post-detection (PD) for nine animals (fitting curves shown as dotted lines): three animals with single point MR monitoring (no fitting) Nude 5, Nude 11 and Nude 13; two cases with 2-point MR monitoring (linear fitting)—Nude 7 and Nude 9 (shown with more detail on the enlarged region displayed as an insert in the upper part of the plot); four cases with more than 2 points (squared polynomial fitting, $\left.r^{2}=0.99-1\right)-N$ ude 1 , Nude 3, Nude 6 and Nude 8. The average growth curve for the monitored masses was calculated from all the fitting curves and was also fitted to a squared polynomial function (solid line error bars, $\pm \mathrm{SD}$ ) to calculate the average tumor duplication time (4-5 days after first detection), $r^{2}=1$
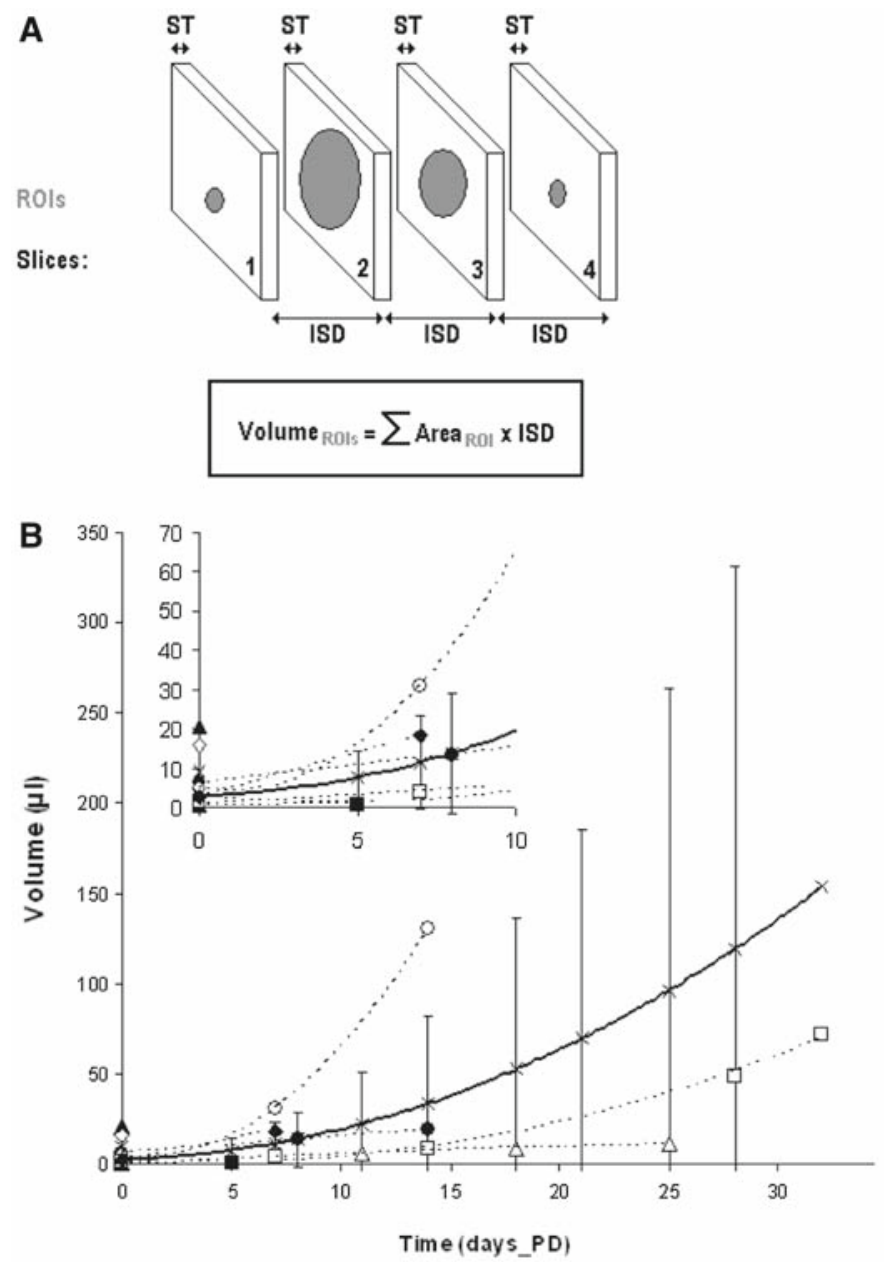

Tumor growth curves

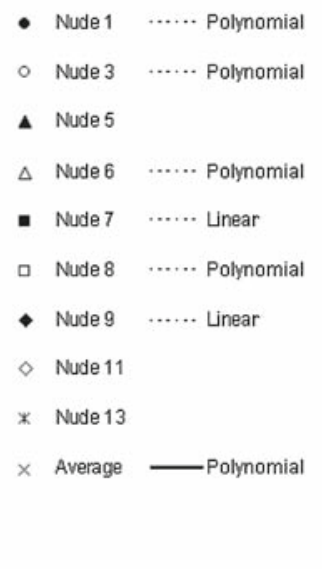

lesions was analyzed in detail in only two cases. As shown in Figs. 5 and 6, good quality spectra were obtained (Nudes 7 and 8 -SNR for the tallest resonance in the spectral range of $4.5-0.0 \mathrm{ppm}$ : 36-70), with $\Delta v_{1 / 2}$ generally around $18-20 \mathrm{~Hz}$ for both the non-suppressed water $(\mathrm{LB}=1 \mathrm{~Hz})$ and metabolite peaks (creatine was used as a reference, $\mathrm{LB}=3 \mathrm{~Hz}$ ).

As shown in Fig. 5a, where the apparent tumor volume for Nude 7 was only $0.74 \%$ and $2.2 \%$ of the total voxel volume used $(27 \mu \mathrm{l})$ at days 46 and 51 post-injection of cells, respectively, there was some decrease in NAAwhile Cho and Cr levels did not seem to be affected: Fig. 5b, c (a small increase in Cho and $\mathrm{Cr}$ was observed, although we cannot rule out here an effect of voxel repositioning in those minor changes). In the 5-week longitudinal study shown in Fig. 6, the spectral changes clearly indicate that, as the tumor volume sampled by the voxel increases, there is a decrease in both $N$-acetyl aspartate (NAA) and creatine $(\mathrm{Cr})$ peak heights and an increase in choline containing compounds (Cho) and mobile lipids (ML) both seen at short TE, as well as lactate (Lac) detection at long TE.

To complement these qualitative analyses, an evolving DSS (SV INTERPRET GUI v1.2) [23,24] was used to tentatively follow the evolution of the spectral pattern detected in our animal model at both long and short TE, as shown in Fig. 6. The normalized spectra of the metastatic human cells growing in nude mice detectable at 7.0 T seem compatible with the human brain tumor patterns obtained at 1.5 T, represented in this DSS. In addition, the evolving pattern of the sampled voxels was concordant with the replacement of normal brain parenchyma (lower right corner of the GUI display) by aggressive tumor cells (upper right corner of the GUI).

\section{Discussion}

Preliminary characterization of brain metastasis growth

Control fluorescence studies, carried out in the initial experiments with CDI mice, confirmed from the initial experiments that the inoculation technique was being performed properly. In our experimental model, brain metastasis progressed in $69 \%$ of the cases ( 9 of 13 animals studied) within a 20 to 62-day time window post-injection, as detected 


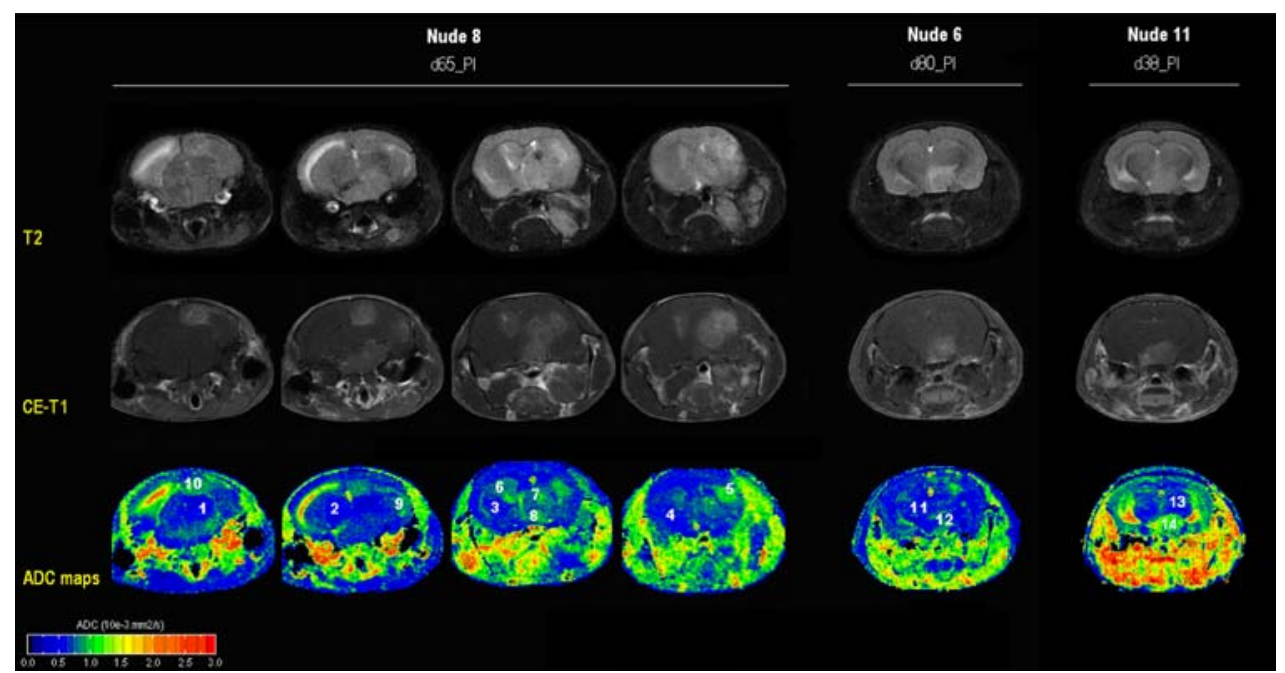

Fig. 3 T2-W, CE-T1 and ADC maps for the same slices. In Nude 8, different coronal slices obtained from neck to snap (left to right). ADC maps perfectly differentiate edema and/or CSF areas (seen in T2-weighed images as brighter areas) from metastasis (regions 5-10, white numbers seen by CE-T1 also as brighter areas), as regions of ADC values higher than the normal brain parenchyma regions (1-4). One metastasis located in the hypothalamus of Nude 6 and Nude 11 is shown in a coronal section both by CE-T1 and ADC maps (regions 12 and 14 , respectively). ADC values measured $\left(10^{-3} \mathrm{~mm}^{2} / \mathrm{s}\right)$ were: $1,0.54 \pm 0.08 ; 2,0.54 \pm 0.08 ; 3,0.58 \pm 0.06 ; 4,0.55 \pm 0.07 ; 5,1.02$ $\pm 0.09 ; 6,0.84 \pm 0.06 ; 7,0.9 \pm 0.12 ; 8,0.92 \pm 0.07 ; 9,0.88 \pm 0.10$; $10,0.88 \pm 0.11 ; 11,0.56 \pm 0.11 ; 12,0.81 \pm 0.09 ; 13,0.45 \pm 0.1 ; 14$, $0.79 \pm 0.12$ in vivo by MR and summarized in Table 1 and Fig. 2b. Metastasis had a heterogeneous distribution when first detected by MRI experiments. This may be correlated with the initial entry point of the cells in the brain parenchyma. Thus, there may be regions where metastatic cells are more prone to extravasate and invade through the blood brain barrier (BBB), although further experiments should to be undertaken to test this assumption. Furthermore, the histological analysis of samples, apart from confirming the metastatic origin of the in vivo-detected brain masses, revealed that two additional animals had brain metastasis (Table 1: Nude 2 and Nude 10). This indicates a total incidence of brain metastasis of $85 \%$ among the population studied (11/13). Therefore, brain micrometastases that were not compromising the BBB integrity at the time of imaging were not detected in vivo by CE-T1 MRI, as expected [10]. Accordingly, they could not be taken into account for MRI-derived volume measurements.

The hypothalamus region seems less prone to allowing metastatic cells to invade the nearby parenchyma, since metastasis growth in this region was slow in the different animals investigated (Fig. 2b, i.e., Nude 6). This may also be related to the presence of other metastases present in the body which could perhaps simulate the effect of a primary tumor that endogenously inhibits the growth of dormant (silent) brain metastatic cells, as proposed by others [30]. Assuming this possibility, the metastatic masses detected in the jaw of 7 animals (54\%, confirmed by histology in one case),
6 of which with MR-detected brain metastasis, are potential sources of such effect. These type of lesions, welldocumented in human breast cancer brain metastasis [2527] and in animal models [28,29], should have originated in our case from some of the inoculated cells that reached the homolateral masticatory muscles through the palatine branch, which derives from the internal carotid artery just before the base of the skull. As the hypothalamus-detected metastases are in close proximity to the circle of Willis, and all its major arterial branches, they could perhaps be influenced by cytokines from nearby jaw tumors. Therefore, an endogenous inhibition effect of brain metastasis growth may explain why the incidence of brain metastases detected here was lower than that reported in previous work [8], although additional experiments would be required to confirm this assumption.

Despite the limitations in the MRI contrast method used, PCNA proliferation indexes (Fig. 4) correlated positively with the in vivo growth rates observed in the cases studied at the time of inspection (although in the case of Nude 9 there are not enough time point inspections to assure that, Fig. $2 b$ seems to suggest it). The PCNA expression profiles therefore suggest that the proliferation of hypothalamus masses in mice without jaw metastases (Nude 3, 82\% proliferation index) was higher than in mice with jaw metastases (Nude 8 and Nude $9,15 \%$ and $65 \%$ proliferation index, respectively) and also that hypothalamus masses displayed higher proliferation arrest as compared to other cerebral metastases present 
Fig. 4 Correlation between in vivo studies and the post-mortem analysis of selected tumor sections (from left to right): CE-T1, H\&E staining $(10 \times$ magnification $)$ and PCNA nuclear expression to measure the proliferative status of brain metastasis $(40 \times$ magnification $)$. a Nude 3, CE-T1 image with the corresponding $\mathrm{H} \& \mathrm{E}$ section and $82 \%$ of PCNA positive cells. b Nude 8, CE-T1 image with three different regions analyzed: sections 1 and 2 with 15 and $29 \%$ of PCNA positive cells, respectively; section 3 with $40 \%$ of positive cells and the corresponding H\&E. c Nude 9, CE-T1 image with two different regions analyzed: section 1 with $65 \%$ of PCNA positive cells, and section 2 with $79 \%$ of PCNA positive cells and the corresponding $\mathrm{H} \& \mathrm{E}$
CE-T1

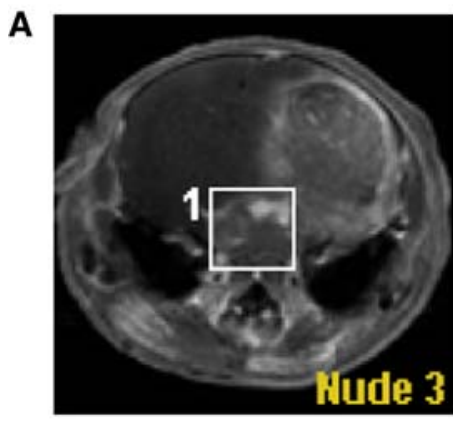

B
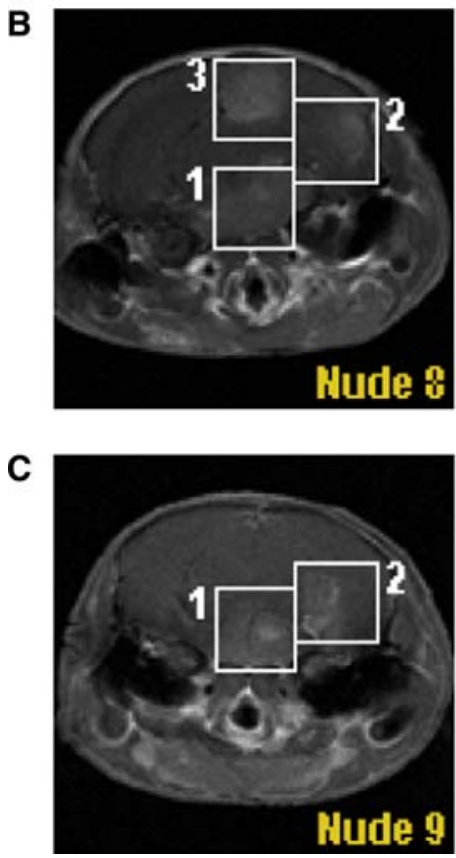

H\&E

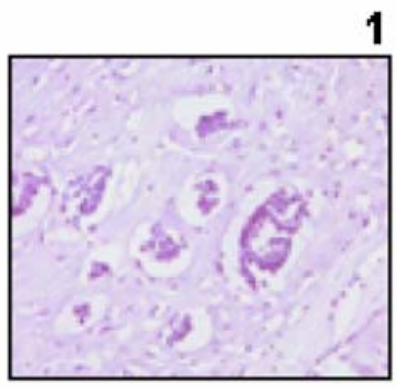

1

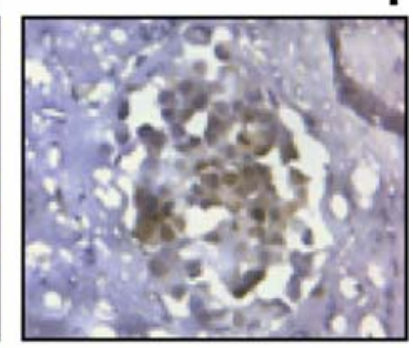

3
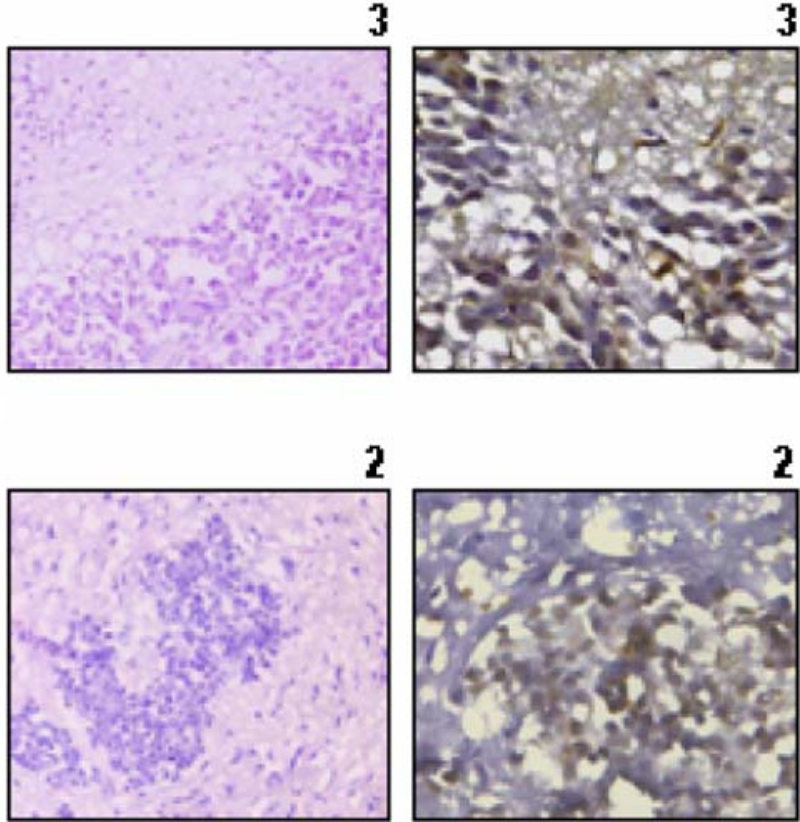

pCNA

1

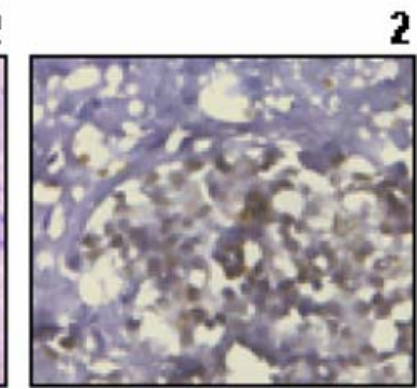

(PCNA proliferation index: Nude 8, 29 and 40\%; Nude 9, $79 \%$ ). Nevertheless, a larger animal cohort would be needed to investigate this possibility.

According to diffusion imaging data (Fig. 3), metastases had higher ADC values than apparently non-afflicted tissues $\left(0.89 \pm 0.07\right.$ vs. $0.56 \pm 0.02 \times 10^{3} \mathrm{~mm}^{2} / \mathrm{s}$, respectively). This would suggest that these are lesions with relatively low cellularity, which is in agreement with other literature on animal models of human tumors [31,32]. Histology studies confirmed this assumption by demonstrating lower cell packing in these masses than in surrounding brain parenchyma (Fig. 4a, H\&E), which should allow water to diffuse more freely.

Regarding MRS monitoring, only cases with good field homogeneity and correct positioning of the voxel inside the lesion were further analyzed (i.e., brain metastases located away from the ear cavities or meninges, which affect shimming due to susceptibility artifacts). Among the 10 cases investigated by MRS, only 8 had brain metastases and just
2 fulfilled this requirement; the field homogeneity was not sufficient to produce good quality spectra in 3 cases, while in other 3 metastases were located in the hypothalamus region of the brain parenchyma, forcing us to sample only a small fraction of the lesion which was sufficiently away from to the ear cavities (voxels containing mostly non-afflicted brain parenchyma).

Even though large voxels were used $(27 \mu \mathrm{l})$, relatively small tumoral masses detected by MRI (micrometastasis $0.2-0.6 \mu \mathrm{l}$ ), along with possibly associated peritumoral effects from the nearby brain parenchyma included in the voxel (i.e., edema [33] and vascular changes [10]), seemed to perturbate the MRS pattern (Fig. 5). In this case, a decrease of $21 \%$ in N-acetyl aspartate (NAA, marker of neuron viability) was the first MRS-based sign of early metastasis growth in the brain. As these lesions increased in size and infiltrated the brain parenchyma (Fig. 6), the spectral changes seen at both short and long TE clearly indicate a substitution of the healthy tissue pattern by a malignant tumor pattern (meta- 


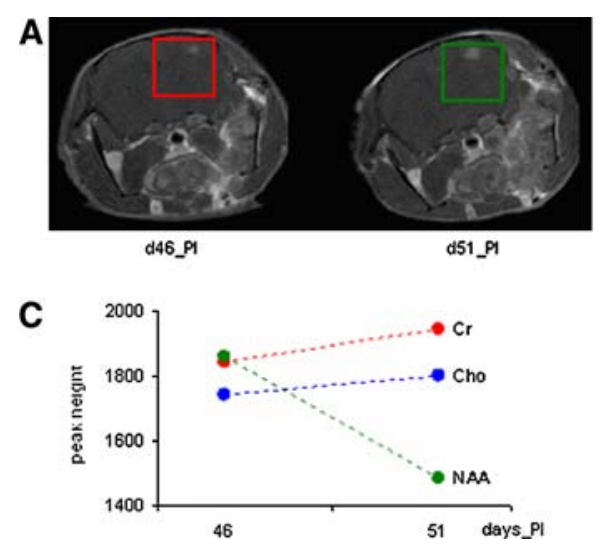

Fig. 5 Longitudinal MRS studies of Nude 7. a Voxel position at each day of study (d46_PI, red square, and d51_PI, green square) shown overlaid into CE-T1 coronal sections obtained at each day of inspection (volume rendering of the metastasis mass gave 0.2 and $0.6 \mu \mathrm{l}$, respec-

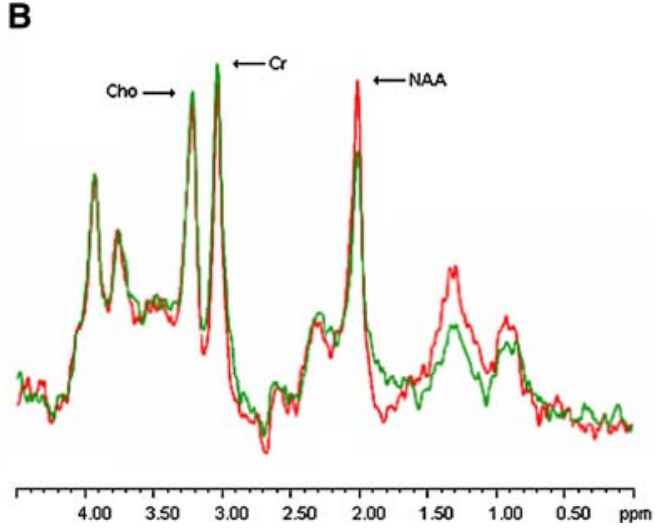

tively). b Short TE ${ }^{1} \mathrm{H}-\mathrm{MRS}$ spectra acquired from the voxels shown in a. c Absolute intensity of selected peaks, arbitrary units (Cho, $3.21 \mathrm{ppm}$; Cr, 3.03 ppm; NAA, $2.03 \mathrm{ppm}$ ) at each day PI

tumor model, it is still able to track the expected change in the sampled spectral pattern from mostly normal brain parenchyma to mostly aggressive tumor. Furthermore, in the last progression stage detected by MRS (day 65 post-injection) the DSS was able to differentiate well the metastasis pattern (human cells growing in nude mice) from non glial tumors, such as meningiomas or low grade glial tumors, positioning the spectra in the glioblastoma- metastasis region, as expected.

Additional remarks and future perspectives

The MDA-MB-435 human breast cancer cell lines have served as the mainstay of brain metastasis work. They have been used to produce brain metastases in experimental assays via infusion into either the carotid artery or the left cardiac ventricle $[6,11]$. The tissue of origin has been a matter of debate since analysis of DNA microarray data indicated that MDA-MB-435 might be of melanocytic origin, due to their similarity to melanoma cell lines [38]. However, our results provide information about the pathogenesis of brain metastasis regardless of the primary tumor location. Another model described for generating brain metastases in nude mice is based on intracardiac injection of the cells. This model has been used to report the occurrence of different metastatic cell populations in the brain [12]. In this case, at day 28 postinjection of MDA-MB-431 mammary carcinoma cells, only $1.5 \%$ of the initially detected cells (day 0 ) were proliferating, while $4.5 \%$ remained as solitary non-proliferating cells. Something similar could also have happened in our work, where we were limited to conventional T2 and Gd-DTPA CET1 MRI methods for detecting areas of compromised BBB, thus missing single cell detection [12] or small cellular tumor masses that had not yet compromised the BBB [10]. As for MRS, spectroscopy techniques with higher resolution should 
Fig. 6 Longitudinal MRS studies of Nude 8. a Voxel position (white squares) shown in both coronal and transversal sections of CE-T1 images obtained at d62_PI. b ${ }^{1} \mathrm{H}-\mathrm{MRS}$ spectra at both short and long TE (top and bottom, respectively), acquired from the voxel shown in $\mathbf{a}$ at different days PI $(37,44$, 51,58 and 62 , color legend at the left of the long TE spectra). c Absolute intensity of selected peaks, arbitrary units (Cho, $3.21 \mathrm{ppm}$; Cr, 3.03 ppm; NAA, $2.03 \mathrm{ppm}$; ML, $1.30 \mathrm{ppm}$, for short TE) at each day PI. Lac is also visible in long TE spectra (1.32 ppm) at days 58 and $62 \mathrm{PI}$. d, e Pattern recognition-based visualization of normalized spectra. Normalized MRS spectra of Nude 8 were entered into the INTERPRET SV DSS $v 1.2$ both for short (a) and long (b) TEs. Each spectrum is represented by two discriminant scores ( $x$ and $y$ axis) calculated by a linear combination of weighted selected peak heights and visualized as a yellow dot on the interface (top-left). On the right, spectra corresponding to days 37 and 62 PI are shown (bottom and top, respectively). Six classification groups are shown on the interface section (left): healthy tissue, white; meningioma, grey; astrocytoma II, blue; astrocytoma III, green; glioblastoma multiforme, red; metastases, pink. The DSS screen suggests a different pattern for the metastasis (human cells growing in nude mice) from non-glial tumors, such as meningiomas, and places the consecutive spectra in a clear progression towards malignancy. Initially, the spectra resemble human cases of healthy tissue, d51_PI. This is then replaced by low grade glial and finally evolves towards an aggressive pattern (Glioblastoma/Metastasis), d62_PI
A

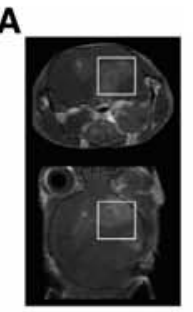

B

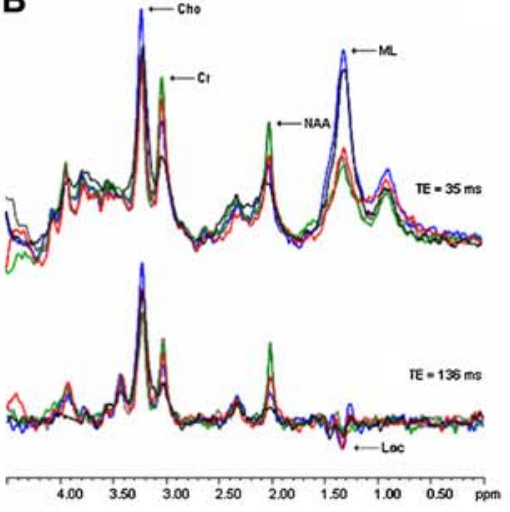

C

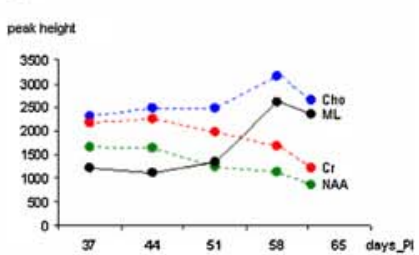

D

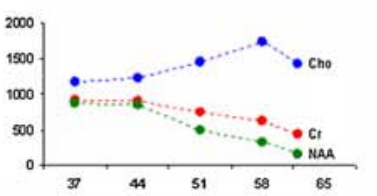

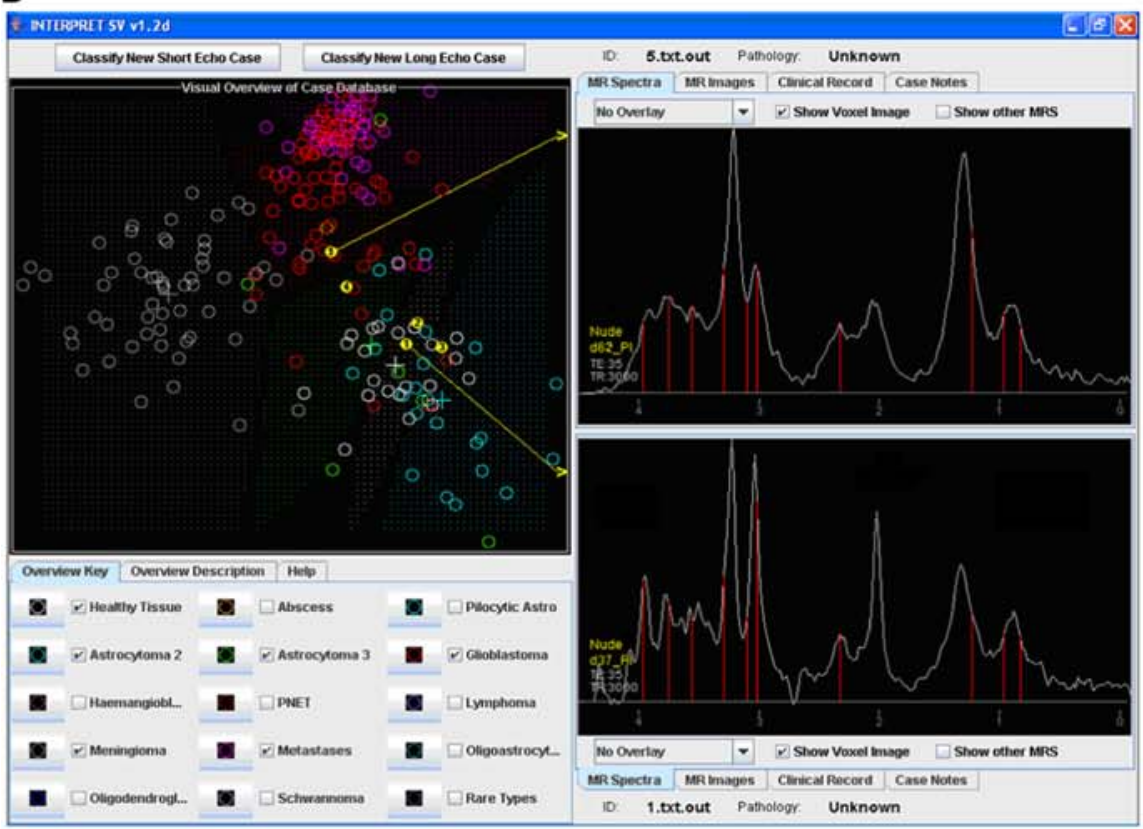

E

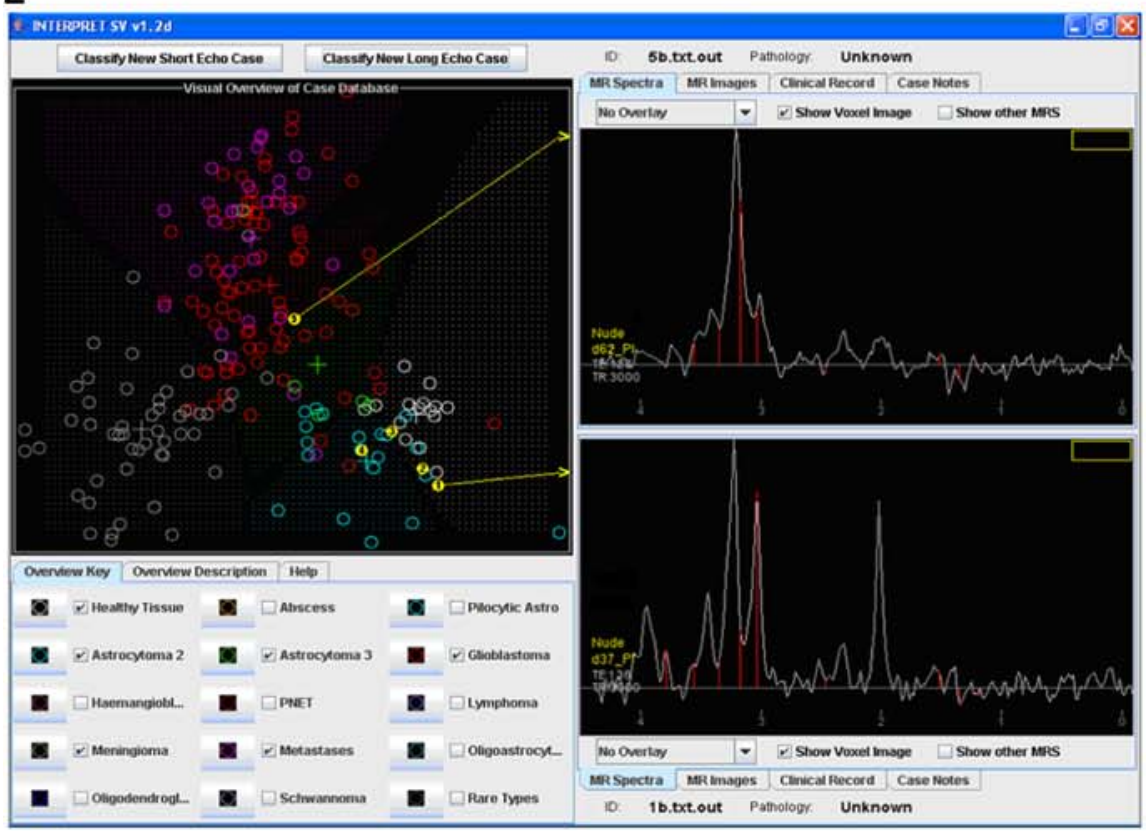


be used. This involves increasing voxel resolution by switching from single-voxel to multi-voxel spectroscopy (chemical shift imaging), as recently described [39].

\section{Conclusions}

The metastasis induction protocol used has demonstrated that MRI and MRS can be used to follow brain metastasis growth kinetics, as confirmed by histological analysis. The qualitative agreement between the PCNA-based proliferation rate and MRI-measured growth kinetics, along with the preliminary pattern recognition analysis of a longitudinal MRS series, opens the way for metastasis growth classification into distinct progression stages and ultimate correlation with human brain metastasis diagnosis and therapy response. In this regard, it is worth considering the potential of the repeated intra-cardiac injection method [11] for further studies. In addition, more sensitive contrast methods should be used for in vivo MRI (intracellular or extracellular iron oxide particles, for single cell detection [12] or as a blood pool agent [10], respectively). Furthermore, localized multi-voxel spectroscopy (chemical shift imaging), already described for the mouse brain [39], should improve the MRS study of this model.

Acknowledgments The authors would like to acknowledge Dr. M.L García-Martín for her support in MRS acquisition work and IDL processing, and Rebeca Sanz for her technical support. This study was funded by the Spanish Ministerio de Ciencia y Tecnologia (SAF 20020440 and SAF 2005-03650), the Portuguese Fundação para a Ciência e a Tecnologia (SFRH/BD/17643/2004), the Spanish Ministerio de Salud y Consumo-Instituto de Salud Carlos III (FIS/PI041937), EC MetaBre (LSHC-CT-2004-506049), and CIBER-BBN (an initiative of Instituto de Salud Carlos III).

\section{References}

1. International Agency for Research on Cancer (WHO). http://www. iarc.fr/. Accessed: 16 Oct, 2007

2. Weil RJ, Palmieri DC, Bronder JL, Stark AM, Steeg PS (2005) Breast cancer metastasis to the central nervous system. Am J Pathol 167:913-920

3. Sierra A (2005) Metastases and their microenvironments: linking pathogenesis and therapy. Drug Resist Updat 8:247-257

4. Carey LA, Ewend MG, Metzger R, Sawyer L, Dees EC, Sartor CI, Moore DT, Graham ML (2004) Central nervous system metastases in women after multimodality therapy for high risk breast cancer. Breast Cancer Res Treat 88:273-280

5. Chambers AF, Groom AC, MacDonald IC (2002) Dissemination and growth of cancer cells in metastatic sites. Nat Rev Cancer 2:563-572

6. Zhang RD, Fidler IJ, Price JE (1991) Relative malignant potential of human breast cancer carcinoma cell lines established from pleural effusions and a brain metastasis. Invas Metast 11:204-215

7. Schackert G, Fidler IJ (1988) Development of in vivo models for studies of brain metastasis. Int J Cancer. 41:589-594
8. Schackert G, Price JE, Bucana CD, Fidler IJ (1989) Unique patterns of brain metastasis produced by different human carcinomas in athymic nude mice. Int J Cancer 44:892-897

9. Dome B, Timar J, Paku S (2003) A novel concept of glomeruloid body formation in experimental cerebral metastases. J Neuropathol Exp Neurol 62:655-661

10. Leenders W, Kusters B, Pikkemaat J, Wesseling P, Ruiter D, Heerschap A, Barentsz J, de Waal RM (2003) Vascular endothelial growth factor-A determines detectability of experimental melanoma brain metastasis in GD-DTPA-enhanced MRI. Int J Cancer 105:437-443

11. Yoneda T, Williams PJ, Hiraga T, Niewolna M, Nishimura $\mathrm{R}$ (2001) A bone-seeking clone exhibits different biological properties from the MDA-MB-231 parental human breast cancer cells and a brain-seeking clone in vivo and in vitro. J Bone Miner Res 16:1486-1495

12. Heyn C, Ronald JA, Ramadan SS, Snir JA, Barry AM, MacKenzie LT, Mikulis DJ, Palmieri D, Bronder JL, Steeg PS, Yoneda T, MacDonald IC, Chambers AF, Rutt BK, Foster PJ (2006) In vivo MRI of cancer cell fate at the single-cell level in a mouse model of breast cancer metastasis to the brain. Magn Reson Med 56:1001-1010

13. Howe FA, Opstad KS (2003) ${ }^{1} \mathrm{H}$ MR spectroscopy of brain tumors and masses. NMR Biomed 16:123-131

14. Griffin JL, Kauppinen RA (2007) A metabolomics perspective of human brain tumours. FEBS J 274:1132-1139

15. Griffin JL, Kauppinen RA (2007) Tumour metabolomics in animal models of human cancer. J Proteome Res 6:498-505

16. Tate AR, Griffiths JR, Martinez-Perez I, Moreno A, Barba I, Cabañas ME, Watson D, Alonso J, Bartumeus $F$, Isamat F, Ferrer I, Vila F, Ferrer E, Capdevila A, Arús C (1998) Towards a method for automated classification of $1 \mathrm{H}$ MRS spectra from brain tumors. NMR Biomed 11:177-191

17. Sierra A, Price JE, Garcia-Ramirez M, Mendez O, Lopez L, Fabra A (1997) Astrocyte-derived cytokines contribute to the metastatic brain specificity of breast cancer cells. Lab Invest 77:357-368

18. Paris S, Sesboue R (2004) Metastasis models:the green fluorescent revolution? Carcinogenesis 25:2285-2292

19. Schmidt CM, Settle SL, Keene JL, Westlin WF, Nickols GA, Griggs DW (1999) Characterization of spontaneous metastasis in an aggressive breast carcinoma model using flow cytometry. Clin Expr Metastasis 17:537-544

20. Al-Attar SA, Pollex RL, Robinson JF, Miskie BA, Walcarius R, Rutt BK, Hegele RA (2006) Semi-automated segmentation and quantification of adipose tissue in calf and thigh by MRI: a preliminary study in patients with monogenic metabolic syndrome. BMC Med Imaging 6:11-19

21. García-Martín ML, Martinez GV, Raghunand N, Sherry AD, Zhang S, Gillies RJ (2006) High resolution $\mathrm{pH}(\mathrm{e})$ imaging of rat glioma using $\mathrm{pH}$-dependent relaxivity. Magn Reson Med 55: 309-315

22. Navarro-Vazquez A, Cobas JC, Sardina FJ, Casanueva J, Diez E (2004) A graphical tool for the prediction of vicinal proton-proton $3 \mathrm{~J}(\mathrm{HH})$ coupling constants. J Chem Inf Comput Sci 44:16801685

23. Interpret Project: http://azizu.uab.es/INTERPRET/. Accessed: 16 Oct 2007

24. Tate AR, Underwood J, Acosta DM, Julià-Sapé M, Majós C, Moreno-Torres A, Howe FA, van der Graaf M, Lefournier V, Murphy MM, Loosemore A, Ladroue C, Wesseling P, Luc Bosson J, Cabañas ME, Simonetti AW, Gajewicz W, Calvar J, Capdevila A, Wilkins PR, Bell BA, Rémy C, Heerschap A, Watson D, Griffiths JR, Arús C (2006) Development of a decision support system for diagnosis and grading of brain tumours using in vivo magnetic resonance single voxel spectra. NMR Biomed 19:411-434 
25. Pilheu FR, Fefer SA (1961) Mandibular metastasis secondary to a cancer of the breast. Sem Med 118:95-97

26. van der Waal RI, Buter J, van der Waal I (2003) Oral metastases: report of 24 cases. Br J Oral Maxillofac Surg 41:3-6

27. Guise TA, Kozlow WM, Heras-Herzig A, Padalecki SS, Yin JJ, Chirgwin JM (2005) Molecular mechanisms of breast cancer metastases to bone. Clin Breast Cancer 5:S46-53

28. Sasaki A, Yoneda T, Terakado N, Alcalde RE, Suzuki A, Matsumura T (1998) Experimental bone metastasis model of the oral and maxillofacial region. Anticancer Res 18:1579-1584

29. Bandyopadhyay A, Elkahloun A, Baysa SJ, Wang L, Sun LZ (2005) Development and gene expression profiling of a metastatic variant of the human breast cancer MDA-MB-435 cells. Cancer Biol Ther 4:168-174

30. Kirsch M, Schackert G, Black PM (2000) Angiogenesis, metastasis, and endogenous inhibition. J Neurooncol 50:173-180

31. Kauppinen RA (2002) Monitoring cytotoxic tumor treatment response by diffusion magnetic resonance imaging and proton spectroscopy. NMR Biomed 15:6-17

32. Sun Y, Mulkern RV, Schmidt K, Doshi S, Albert MS, Schmidt NO, Ziu M, Black P, Carrol R, Kieran MW (2004) Quantification of water diffusion and relaxation times of human U87 tumors in a mouse model. NMR Biomed 17:399-404

33. Lu S, Ahn D, Johnson G, Cha S (2003) Peritumoral diffusion tensor imaging of high-grade gliomas and metastatic brain tumors. AJNR Am J Neuroradiol 24:937-941

34. García-Martín ML, Herigault G, Rémy C, Farion R, Ballesteros P, Coles JA, Cerdán S, Ziegler A (2001) Mapping extracellular pH in rat brain gliomas in vivo by $1 \mathrm{H}$ magnetic resonance spectroscopic imaging: comparison with maps of metabolites. Cancer Res 61:6524-6531

35. Rémy C, Arús C, Ziegler A, Lai ES, Moreno A, Le Fur Y, Decorps M (1994) In vivo, ex vivo, and in vitro one- and two-dimensional nuclear magnetic resonance spectroscopy of an intracerebral glioma in rat brain: assignment of resonances. J Neurochem 62:166179

36. Barba I, Cabañas ME, Arús C (1999) The relationship between nuclear magnetic resonance-visible lipids, lipid droplets, and cell proliferation in cultured C6 cells. Cancer Res 59:1861-1868

37. Rémy C, Fouilhe N, Barba I, Sam-Lai E, Lahrech H, Cucurella MG, Izquierdo M, Moreno A, Ziegler A, Massarelli R, Decorps M, Arús C (1997) Evidence that mobile lipids detected in rat brain glioma by $1 \mathrm{H}$ nuclear magnetic resonance correspond to lipid droplets. Cancer Res 57:407-414

38. Ross DT, Scherf U, Eisen MB, Perou CM, Rees C, Spellman P, Iyer V, Jeffrey SS, Van de Rijn M, Waltham M, Pergamenschikov A, Lee JC, Lashkari D, Shalon D, Myers TG, Weinstein JN, Botstein D, Brown PO (2000) Systematic variation in gene expression patterns in human cancer cell lines. Nat Genet 24:227-235

39. Diekman C, Simões RV, Pohman R, Cerdán S, Arús C (2006) Proton chemical shift imaging of mouse brain tumors at $7 \mathrm{~T}$. Bruker SpinReport. 2006; 157:18-21 http://www.bruker-biospin. com/spin_report.html 